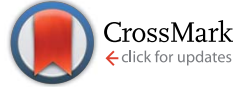

Cite this: RSC Adv., 2015, 5, 17976
Received 14th January 2015 Accepted 4th February 2015 DOI: $10.1039 / c 5 r a 00803 d$ www.rsc.org/advances

\section{Optimization of a liquid chromatography-tandem mass spectrometry method for the quantification of traces of taxanes in a Corylus avellana cell suspension medium}

\author{
Ana Gallego, ${ }^{a}$ Olga Jáuregui, ${ }^{\mathrm{b}}$ Elisabeth Moyano, ${ }^{\mathrm{a}}$ Javier Palazón, ${ }^{\mathrm{c}}$ Isidre Casals ${ }^{\mathrm{b}}$ \\ and Mercedes Bonfill*c
}

\begin{abstract}
Since the recent discovery of taxol and other taxanes in Corylus avellana, this plant species has attracted interest as a potential new source of these compounds. However, its low taxane content in comparison with Taxus spp. has restricted research to analytical identification or global quantitation. A feasible and sensitive method based on liquid chromatography-tandem mass spectrometry using a triple quadrupole analyzer was developed for the analysis of taxol and four other taxanes in a Corylus avellana cell suspension medium. Taxanes were extracted from the cell culture medium with dichloromethane and analyzed using electrospray ionization and quantified by multiple-reaction monitoring mode. Methanol and matrix-matching calibration curves using docetaxel as the internal standard were analyzed. Linearity was confirmed over the whole calibration range $\left(0.3-2.1 \mu \mathrm{g} \mathrm{mL} \mathrm{L}^{-1}\right)$. The inter- and intra-day precision of taxanes ranged from $80 \%$ to $120 \%$ and the recovery rates were higher than $80 \%$. Limits of detection were between $0.24-38 \mathrm{ng} \mathrm{mL}^{-1}$ and the limits of quantification were between $0.8-125 \mathrm{ng} \mathrm{mL}^{-1}$. The low detection and quantitation values obtained allowed us to detect small quantities of the released taxanes (120 $\mathrm{ng} \mathrm{mL}^{-1}$ of $\mathrm{B}, 151 \mathrm{ng} \mathrm{mL}^{-1}$ of $\mathrm{CF}$ and $105 \mathrm{ng} \mathrm{mL}^{-1}$ of T), which correspond to about $0.5 \mathrm{ng}$ $\mathrm{mL}^{-1}$ of each taxane, in the $20 \mathrm{~mL}$ Corylus avellana cell suspension culture medium extracted, even at the beginning of the culture. These results were confirmed by high resolution mass spectrometry.
\end{abstract}

\section{Introduction}

Taxanes, particularly taxol, are phytochemicals with high added value. Since the discovery of taxol in 1967 in Taxus brevifolia, more than 500 natural taxanes have been characterized in different Taxus spp., as well as a huge number of synthetic taxol analogues. ${ }^{1-3}$

Taxanes have an important effect against several types of human cancer, including ovarian, breast, head, neck and small cell and non-small cell lung cancers. Their effectiveness in treating AIDS-related Kaposi's sarcoma, lymphoma, and prostate, gastric and bladder cancers has also been recently shown. ${ }^{4-7}$ Taxanes are classified as microtubule-interfering agents because they are able to bind with the microtubules and block the cell cycle in the metaphase-anaphase transition, forming highly stable microtubules by suppressing their depolymerization. ${ }^{8}$

${ }^{a}$ Departament de Ciències Experimentals $i$ de la Salut, Universitat Pompeu Fabra, Avda. Dr. Aiguader 80, E-08003, Barcelona, Catalonia, Spain

${ }^{b}$ Scientific \& Technological Centers, Universitat de Barcelona (CCiTUB), c/Baldiri $i$, Reixach 10-12, 08028 Barcelona, Catalonia, Spain

'Laboratorio de Fisiología Vegetal, Facultad de Farmacia, Universidad de Barcelona, Avda. Diagonal 643, E-08028 Barcelona, Catalonia, Spain. E-mail: mbonfill@ub. edu; Fax: +34 934029043; Tel: +34934020267
Due to the high commercial demand for taxol and its low content in Taxus spp., there is a growing interest in exploring new strategies for its production at an industrial level. These include total synthesis, semi-synthetic processes from more abundant taxanes (such as baccatin III, 10-deacetylbaccatin III, 10-deacetyltaxol and cephalomannine), and biotechnological production using cell suspension cultures of Taxus spp. or other taxane-producing species such as Corylus avellana or fungi. ${ }^{2}$ Plant cell cultures constitute an emerging technology for the production of high-value secondary metabolites, which can be scaled up to bioreactor level. They also avoid supply problems associated with the natural sources of these compounds or traditional plant cultivation. An interesting feature of in vitro plant cells is their ability to release secondary metabolites into the culture medium, thereby facilitating the in situ recovery of the product and promoting a continuous production by the cells. Thus, extracellular availability of the target compounds is preferable to their intracellular extraction from the cells.

To our knowledge, taxol was first found in C. avellana trees by Hoffman et al. (1998), and since then, the advantages of plant cell cultures have been harnessed to enhance taxol yields in $C$. avellana cell suspensions by different strategies, including elicitation..$^{9-12}$ 
Different methodologies to determine taxol and other taxanes are available, most of them using high performance liquid chromatography (HPLC) or Enzyme-Linked ImmunoSorbent Assays (ELISA). HPLC-mass spectrometry (HPLC-MS) has also been used to identify and characterize taxanes in plant samples and cell suspension cultures but not to quantify them, so it was necessary to develop a new reliable methodology to quantify these compounds. ${ }^{9,13}$ HPLC-MS/MS is a powerful technique to quantify and determine drugs and metabolites from biological samples, due to its inherent specificity, sensitivity and speed. The HPLC system allows us to separate all the compounds present in the sample extracts, permitting independent MS analysis of the parent ion, which undergoes a selective fragmentation that can be monitored. Moreover, this methodology allows compounds to be detected at trace levels with high reliability.

Although an HPLC-MS/MS method has been described for taxane analysis in Taxus spp. plant extracts, no HPLC-MS/MS method has been available to determine the low content of taxol and taxanes found in cell suspension cultures or in $C$. avellana extracts. ${ }^{\mathbf{1 4}}$ In addition to the problems arising from matrix complexity, the taxane content in the $C$. avellana tree is ten times lower than in Taxus spp. ${ }^{9}$ It was therefore necessary to develop a suitable method, including extraction and quantification, able to overcome the matrix issues and detect small quantities of each taxane. The high sensitivity of HPLC-MS/MS methods, especially in multiple-reaction monitoring mode (MRM), indicated it was a suitable technique for taxane analysis in $C$. avellana samples.

In the present work we developed a sensitive HPLC-MS/MS method to quantify five of the most commercially important taxanes: the therapeutic compound taxol, and baccatin III, 10deacetylbaccatin III, 10-deacetyltaxol and cephalomannine, which can be used for the semi-synthetic production of taxol. Multiple-reaction monitoring mode was used to maximize sensitivity and a positive identification of these compounds by high resolution mass spectrometry (HPLC-ITD-FTMS) was achieved. C. avellana cell suspensions were established and the taxanes released into the culture medium were determined and quantified using the reliable analytical method developed. This constitutes the first step in the scale-up process of continuous cultures associated with in situ product removal.

\section{Experimental}

\subsection{Chemicals and reagents}

All the reagents used were HPLC grade. Methanol, hexane and dichloromethane were purchased from Teknokroma ${ }^{\circledR}$ (Sant Cugat, Barcelona, Spain), acetonitrile LC-MS from Sigma (Madrid, Spain), and MilliQ water was obtained using a Milli-Q system (Millipore). Standards of taxanes, 10-deacetylbaccatin III (DB), baccatin III (B), 10-deacetyltaxol (DT), cephalomannine (CF) and taxol (T), from ChromaDex ${ }^{\mathrm{TM}}$ were used to prepare the calibration curves. Docetaxel (DTX), used as an internal standard (IS), was also obtained from ChromaDex ${ }^{\mathrm{TM}}$. PVDF syringe filters (13 mm, $0.22 \mu \mathrm{M}$ pore size) from Teknokroma ${ }^{\circledR}$ were used to filter standard solutions and samples.

\subsection{Preparation of standard solutions}

Standard stock solutions were prepared in methanol at $50 \mu \mathrm{g}$ $\mathrm{mL}^{-1}$ and kept at $-20{ }^{\circ} \mathrm{C}$ until use. For the working standard solutions, 10-deacetylbaccatin III, baccatin III, 10-deacetyltaxol, cephalomannine and taxol were dissolved in methanol $(\mathrm{MeOH})$ to obtain seven standard solutions with concentrations in the range of $0.3-2.1 \mu \mathrm{g} \mathrm{mL} \mathrm{mL}^{-1}$. A stock solution of $50 \mu \mathrm{g} \mathrm{mL}$ docetaxel (IS) was prepared in $\mathrm{MeOH}$, and further dilutions were also made in methanol. To carry out the analysis, $5 \mu \mathrm{L}$ of stock solution was added to samples before the extraction to obtain a final concentration of $1 \mu \mathrm{g} \mathrm{mL}^{-1}$.

\subsection{HPLC-MS/MS conditions}

2.3.1 HPLC conditions. The HPLC system consisted of an Agilent 1100 chromatograph fitted with a quaternary pump, a refrigerated autosampler and a UV detector. A Supelcosil ${ }^{\mathrm{TM}}$ LC-F $5 \mu \mathrm{m}(25 \mathrm{~cm} \times 4.6 \mathrm{~mm})$ column (Supelco, Bellefonte, USA) was used. The mobile phase consisted of water (A) and acetonitrile (B) with the following gradient $(t$ (min), \% B): $(0,25),(28,50)$, $(28.5,90),(32,90),(32.5,25),(40,25)$. The flow rate was $1.00 \mathrm{~mL}$ $\min ^{-1}$, and a $1 / 3$ split was done before the MS. The column was maintained at room temperature and the wavelength was set at $225 \mathrm{~nm}$. Injection volume was $10 \mu \mathrm{L}$.

2.3.2 MS/MS conditions. The HPLC system was coupled to a triple quadrupole mass spectrometer API 3000 (AB Sciex, Ontario, CA) fitted with a TurboIon spray source working in positive ion mode and using the following settings: nebulizer gas $\left(\mathrm{N}_{2}\right)$ at 9 (arbitrary units), curtain gas $\left(\mathrm{N}_{2}\right)$ at 10 (arbitrary units), auxiliary gas $\left(\mathrm{N}_{2}\right)$ at $8000 \mathrm{~cm}^{3} \mathrm{~min}^{-1}$, heated at $400{ }^{\circ} \mathrm{C}$, ion spray voltage at $+5 \mathrm{kV}, \mathrm{CAD}$ gas $\left(\mathrm{N}_{2}\right)$ at 5 (arbitrary units), declustering potential DP at $+60 \mathrm{~V}$, focusing potential $\mathrm{FP}$ at +200 $\mathrm{V}$, entrance potential at $+10 \mathrm{~V}$, collision energy at $+20 \mathrm{~V}$, and collision cell exit potential CXP at $+15 \mathrm{~V}$. MS and MS/MS parameters have been established through infusion experiments using a Harvard syringe pump at $10 \mu \mathrm{L} \mathrm{min}^{-1}$ (individual standard solution at $1 \mathrm{mg} \mathrm{L}^{-1}$ ) in acetonitrile-water $1: 1$.

In order to achieve the highest sensitivity, MRM was the acquisition method of choice, all the transitions (Table 1) having a dwell time of $80 \mathrm{~ms}$. Identification and confirmation transitions were determined for each compound. Taxanes were identified by comparing retention times with the standards in MRM trace chromatograms. Data were acquired and analyzed using analyst 1.4.2 software.

\subsection{HPLC-ITD-FTMS}

An Accela chromatograph (Thermo Scientific, San Jose; CA,USA) was coupled to an LTQ-Orbitrap Velos instrument (Thermo Scientific, San Jose; CA, USA). A Supelcosil ${ }^{\mathrm{TM}}$ LC-F $5 \mu \mathrm{m}(25 \mathrm{~cm}$ $\times 4.6 \mathrm{~mm}$ ) column (Supelco, Bellefonte, USA) was used and the chromatographic conditions were the same as for the triple quadrupole system. All the analyses were done in positive mode with the following MS conditions: full scan analysis from $\mathrm{m} / \mathrm{z}$ 100 to 1100 at 30000 resolution using the FTMS. 
Table 1 Parameters of the HPLC-MS/MS analysis of taxanes: (a) molecular weight (Da), (b) retention time (min); the two MRM transitions for each compound correspond to the identification transition and confirmation transition (*). DP was fixed at $60 \mathrm{~V}$ for all compounds

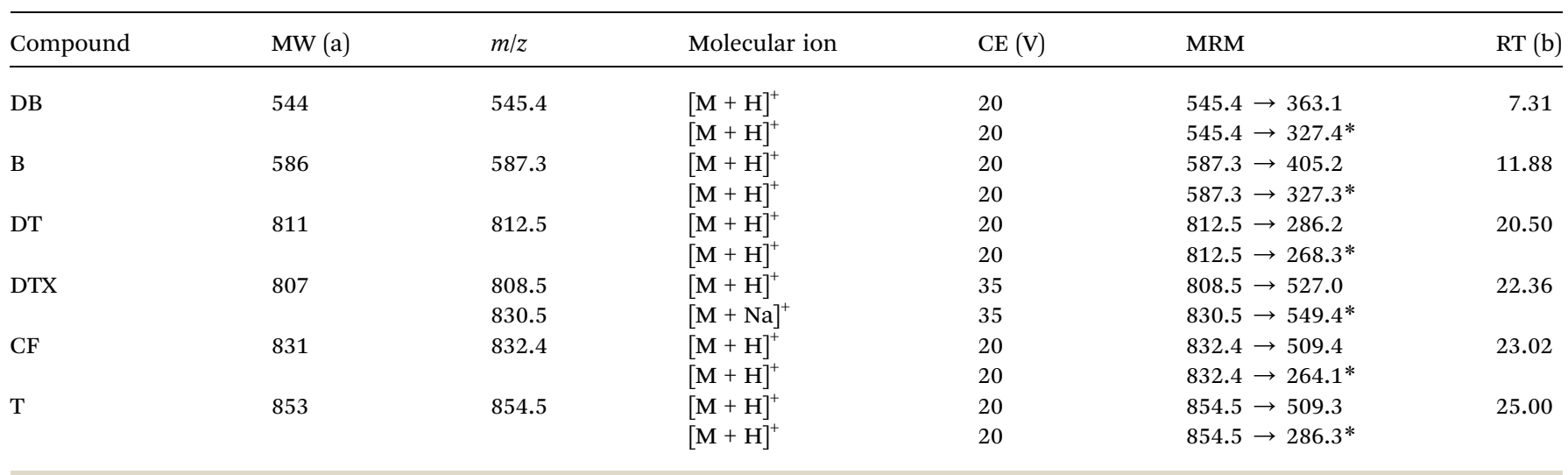

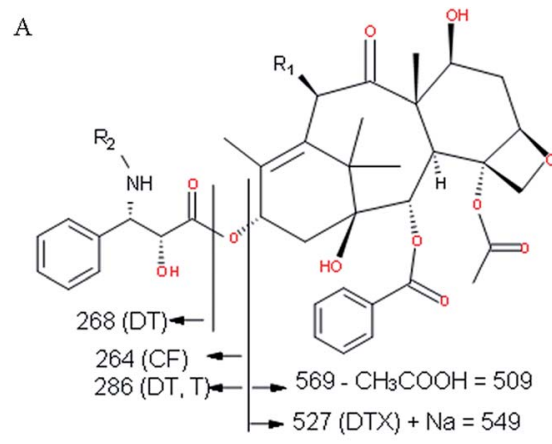

A) Common structure for taxol, 10-deacetyltaxol, cephalomannine and docetaxel T: R1 acetoxy group; R2 benzoyl group

DT: R1: hydroxyl group; R2: benzoyl group

CF: R1: acetoxy group; R2: N-Tigloyl group

DTX: R1: hydroxyl group; R2: tert-Butyloxycarbonyl

B

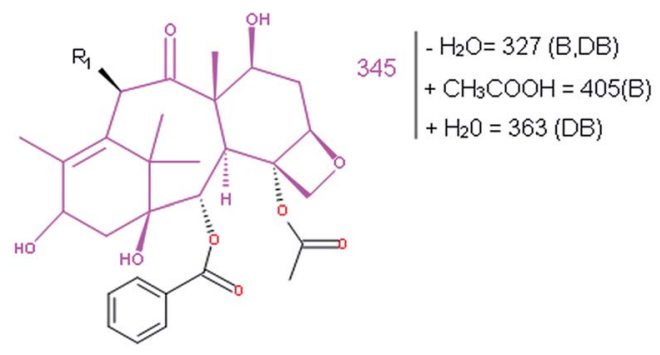

B) Common structure for baccatin III and 10-deacetylbaccatin III

B: R1: acetoxy group

DB: R1: hydroxyl group

Fig. 1 (a) The common structure for taxol (T), 10-deacetyltaxol (DT) cephalomannine (CF) and docetaxel (DTX). Fragments for each compound are represented. (b) The common structure for baccatin III (B) and 10-deacetylbaccatin III (DB). The fragmentation profile is based on $\mathrm{m} / \mathrm{z} 345$ (baccatin core) with the described additions and losses.

\subsection{Plant material}

C. avellana cell suspensions were established from selected white and friable callus induced from hazelnuts. $3 \mathrm{~g}$ of calli were inoculated in $30 \mathrm{~mL}$ of Murashige and Skoog medium, ${ }^{15}$ supplemented with sucrose at $30 \mathrm{~g} \mathrm{~L}^{-1}, 2$,4-dichlorophenoxyacetic acid $2 \mathrm{mg} \mathrm{L}^{-1}$ and kinetin $0.4 \mathrm{mg} \mathrm{L}^{-1}$. The cell cultures were maintained in $200 \mathrm{~mL}$ flasks at $25^{\circ} \mathrm{C}$ in the dark on an orbital shaker at $110 \mathrm{rpm}$ and were routinely subcultured every 15 days until a fine suspension was obtained, establishing different cell suspension lines. The different cell lines were preliminarily screened for their taxane content. The cultures without taxanes, or with a taxane content below the limit of detection, were used for optimization purposes (calculations of the limit of detection (LOD), limit of quantitation (LOQ), recovery, and matrix effect) and also to obtain the matrix-matching calibration curve, while those containing taxanes were analyzed with the optimized method.

\subsection{Sample preparation}

Taxanes in the C. avellana cell culture medium $(20 \mathrm{~mL})$ were extracted using $2 \mathrm{~mL}$ of dichloromethane for each $10 \mathrm{~mL}$ of medium, vortexed for 2 minutes and sonicated (40 kHz, Branson) for 1 hour. The organic phase was dried with nitrogen gas, dissolved in $250 \mu \mathrm{L}$ methanol and filtered through a PVDF 0.22 $\mu \mathrm{M}$ filter for subsequent analysis. Samples used for optimization purposes, from cell lines without taxanes, were extracted using the same procedure.

\subsection{Quality parameters}

2.7.1 Linearity: limits of detection and quantification. Calibration curves were done by plotting the analyte area/IS area versus the analyte concentration/IS concentration and weighted using $1 / x^{2}$, obtaining correlation coefficients $\left(r^{2}\right)$ higher than 0.99 and an accuracy in the determination of standard concentration between $80-120 \% .^{16}$ The standard curve was run on three different days in order to evaluate the stability and linearity of our method. Also, the LOD as the concentration with a signal-to-noise $(S / N)$ of 3 and LOQ as the concentration with a signal to noise $(S / N)$ of 10 were determined.

2.7.2 Precision and accuracy. An intermediate concentration of standard solution $\left(1.2 \mu \mathrm{g} \mathrm{mL}{ }^{-1}\right)$ was injected eight times to evaluate intra and inter-day accuracy and precision. Quantification was carried out using a calibration curve from the same batch.

2.7.3 Recovery and matrix effect. Recovery and matrix effect were evaluated by the standard addition method, spiking samples pre- and post-extraction, respectively. In the pre- 

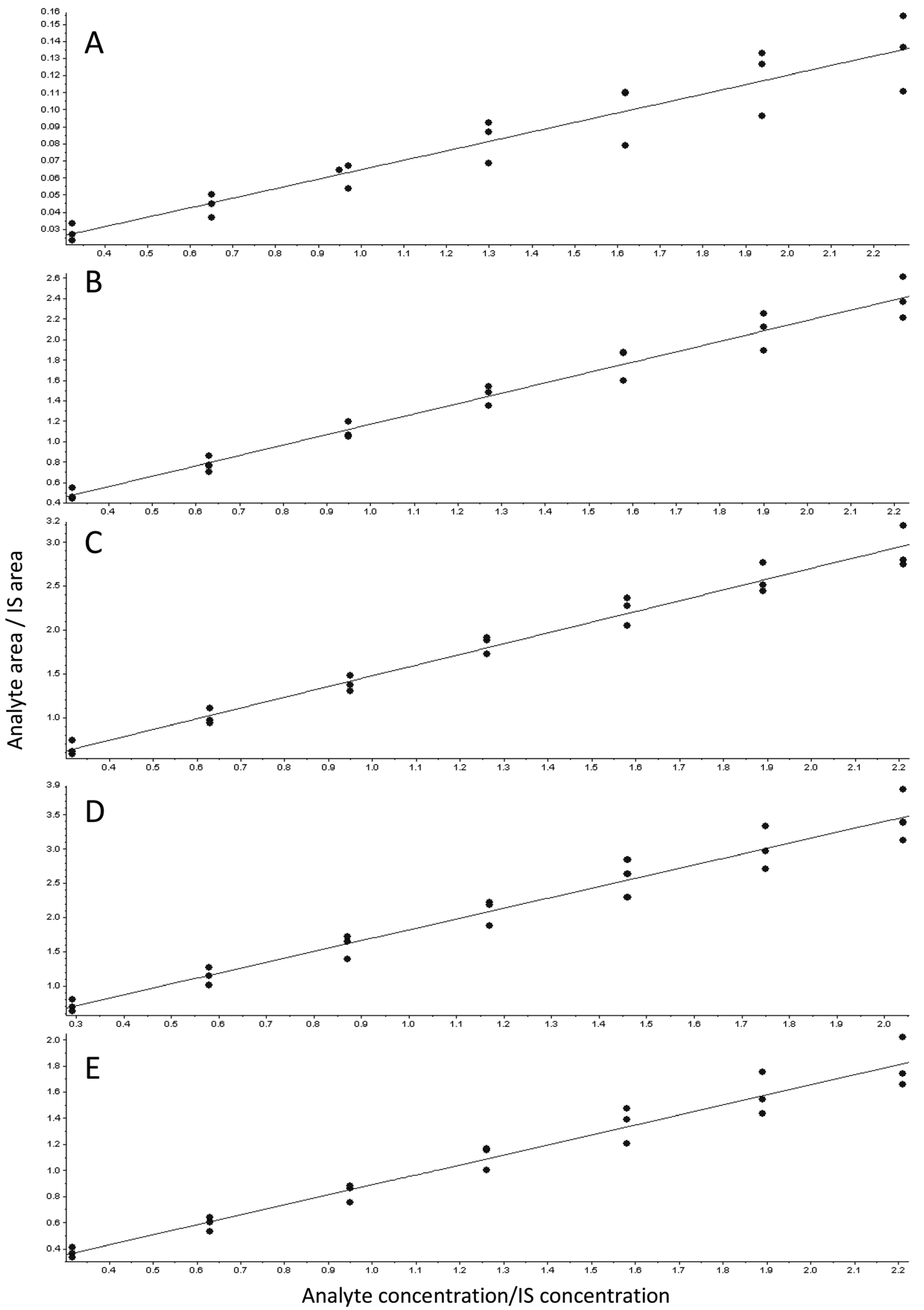

Fig. 2 Standard curves of 10-deacetylbaccatin III (a), baccatin III (b), 10-deacetyltaxol (c), cephalomannine (d) and taxol (e) in the range of 0.3-2.1 $\mu \mathrm{g} \mathrm{mL}^{-1} .1 \mu \mathrm{g} \mathrm{mL} \mathrm{m}^{-1}$ of DTX was added as the internal standard (IS), therefore the analyte area/IS area vs. analyte concentration is represented. 
Table 2 Mean, relative standard deviation (RSD) and accuracy for each compound regarding the three different standard curves $(1,2,3)$. Th.C: theoretical concentration. DB: 10-deacetylbaccatin III. B: baccatin III. DT: 10-deacetyltaxol. CF: cephalomannine. T: taxol

\begin{tabular}{|c|c|c|c|c|c|}
\hline & Intra-day & Th.C. $\left(\mu \mathrm{g} \mathrm{mL}^{-1}\right)$ & Mean $(n=8)$ & RSD (\%) & Accuracy (\%) \\
\hline \multirow[t]{3}{*}{ DB } & 1 & 1.30 & 1.26 & 1.9 & 96.9 \\
\hline & 2 & & 1.13 & 4.7 & 86.6 \\
\hline & 3 & & 1.60 & 1.5 & 119.0 \\
\hline \multirow[t]{3}{*}{ B } & 1 & 1.27 & 1.29 & 2.2 & 101.3 \\
\hline & 2 & & 1.12 & 3.2 & 88.0 \\
\hline & 3 & & 1.40 & 4.6 & 110.6 \\
\hline \multirow[t]{3}{*}{ DT } & 1 & 1.26 & 1.28 & 1.8 & 101.6 \\
\hline & 2 & & 1.10 & 4.9 & 87.3 \\
\hline & 3 & & 1.38 & 7.7 & 109.7 \\
\hline \multirow[t]{3}{*}{$\mathrm{CF}$} & 1 & 1.17 & 1.20 & 2.5 & 102.6 \\
\hline & 2 & & 1.03 & 4.7 & 88.3 \\
\hline & 3 & & 1.42 & 5.2 & 119.3 \\
\hline \multirow[t]{3}{*}{$\mathrm{T}$} & 1 & 1.26 & 1.28 & 2.9 & 101.9 \\
\hline & 2 & & 1.13 & 4.1 & 89.8 \\
\hline & 3 & & 1.50 & 5.1 & 119.2 \\
\hline \multicolumn{2}{|c|}{ Inter-day } & Mean $(n=24)$ & \multicolumn{2}{|c|}{ RSD (\%) } & Accuracy (\%) \\
\hline \multicolumn{2}{|l|}{ DB } & 1.33 & \multicolumn{2}{|l|}{15.7} & 102.2 \\
\hline \multicolumn{2}{|l|}{ B } & 1.27 & \multicolumn{2}{|l|}{10.1} & 99.9 \\
\hline \multicolumn{2}{|l|}{ DT } & 1.25 & \multicolumn{2}{|l|}{10.9} & 98.7 \\
\hline \multicolumn{2}{|l|}{$\mathrm{CF}$} & 1.22 & \multicolumn{2}{|l|}{14.0} & 104.0 \\
\hline \multicolumn{2}{|l|}{$\mathrm{T}$} & 1.31 & \multicolumn{2}{|l|}{12.7} & 103.7 \\
\hline
\end{tabular}

extraction, $25 \mu \mathrm{L}$ of taxanes stock solution in $\mathrm{MeOH}$ at $50 \mu \mathrm{g}$ $\mathrm{mL}^{-1}$ was added to $20 \mathrm{~mL}$ of the $C$. avellana culture medium to obtain a final concentration of $5 \mu \mathrm{g} \mathrm{mL}{ }^{-1}$. The taxane extraction was then carried out as described before, and dried down. In the post-extraction addition, the same amount of taxane stock solution in $\mathrm{MeOH}$ was added to the dried-down extracts and reevaporated. $5 \mu \mathrm{L}$ of the DTX standard solution at $50 \mu \mathrm{g} \mathrm{mL}{ }^{-1}$ was added before the extraction. Samples were resuspended in $250 \mu \mathrm{L}$ of $\mathrm{MeOH}$.

\subsection{Matrix-matching calibration curve}

The same range of concentrations as in the standard curve in methanol was added to a non-taxane-containing $C$. avellana cell culture medium extract to obtain the points of the matrix-based calibration curve. The additions were carried out before the extraction. Also, in each case $1 \mu \mathrm{g} \mathrm{mL}^{-1}$ of the DTX as the internal standard was added before the extraction. Taxane extraction was carried out as described before, and the dried-down extracts were resuspended in $250 \mu \mathrm{L}$ of $\mathrm{MeOH}$. Extractions were carried out in duplicate for each concentration.

\section{Results and discussion}

Electrospray ionization (ESI) was tested in both positive and negative ion modes, with a higher response found in the former. Therefore, the ESI source in positive ion mode was chosen for taxane detection. The mass spectra were recorded in the range of $m / z 100-1000$ amu. The main ions obtained from the standards were as follows: DB: $m / z 545.4[\mathrm{M}+\mathrm{H}]^{+}$, B: $m / z 587.3[\mathrm{M}+\mathrm{H}]^{+}$, DT: $m / z 812.5[\mathrm{M}+\mathrm{H}]^{+}, \mathrm{CF}: m / z$ 832.4 [M + $\mathrm{H}]^{+}, \mathrm{T}: m / z 854.5[\mathrm{M}+\mathrm{H}]^{+}$, and DTX: $m / z 808.5[\mathrm{M}+\mathrm{H}]^{+}$. Also, $m / z 830.5[\mathrm{M}+\mathrm{Na}]^{+}$was observed for DTX. Since declustering potential (DP) and collision energy (CE) played a significant role in generating the final MRM mode, both parameters were optimized in order to have the maximum signal for each analyte in infusion experiments (DP $60 \mathrm{~V}$ and CE 25-30 V). Identification transitions, which were defined as those with highest intensity, and the confirmation transitions obtained are shown in Table 1.

McClure et al. (1992) and Kerns et al. (1994) reported the fragmentation pattern of taxol and 19 natural taxanes, describing the fragment ion characteristic of the paclitaxel core as $\mathrm{m} / \mathrm{z}$ 509. The target compounds showed lateral chains with different $m / z$ fragments: $m / z 286$ in the case of T, $m / z 286$ and $m / z 268$ for DT, and $m / z 264$ for CF. Also, $m / z 327$ was thought to correspond to the baccatin III core after water loss. ${ }^{13,17}$ Similarly, we hypothesize that $\mathrm{m} / \mathrm{z} 405$ corresponds to the baccatin III core with a carboxylic acid substitution, and $m / z 363$ to the baccatin III core with water incorporation. The Multiple Reaction Monitoring (MRM) transitions for DTX are $m / z 808.5 \rightarrow 527.0$, described by Corona et al. (2011), and $m / z 830.5 \rightarrow 549.4$ corresponding to the $\mathrm{Na}^{+}$adduct. ${ }^{18}$ Fig. 1 depicts the common structure for each compound, and the different fragments used for their identification. Although some $\mathrm{m} / \mathrm{z}$ fragments were already described, only a descriptive fragmentation was usually reported, and there are no studies available combining these data with the evaluation of the quality parameters and with the quantification using a matrix-matching calibration curve.

\subsection{Linearity}

The standard curve analysis before the use of the IS showed an increasing angle of slope during the three days (data not shown). To solve this problem, we searched for a suitable IS. Taking into account that an IS should be a compound of the same chemical class as the analytes but with different molecular weight and different MRM transitions, we chose DTX as an appropriate IS to determine the taxanes in our samples, since it fulfilled the aforementioned requirements. Moreover, as a synthetic analogue, it was not present in our samples.

The linearity of the chromatographic method was determined using a mixed standard solution of DB, B, DT, CF and T at seven concentrations in the range of $0.3-2.1 \mu \mathrm{g} \mathrm{mL}{ }^{-1}$ supplemented with $1 \mu \mathrm{g} \mathrm{mL} \mathrm{mL}^{-1}$ of the IS DTX. The graph therefore represents the analyte area/IS analyte area vs. analyte concentration/IS concentration (Fig. 2). The regression equation and the correlation coefficients of each compound in each standard curve were determined. $R^{2}$ was higher than 0.997 for all the compounds in the three different standard curves, showing a good linearity over the measured range and allowing a good extrapolation of our data. Weighted least squares linear regression by a factor of $1 / x^{2}$ resulted in an accuracy range of $80-120 \%$ in terms of RSD. ${ }^{16}$ 
A
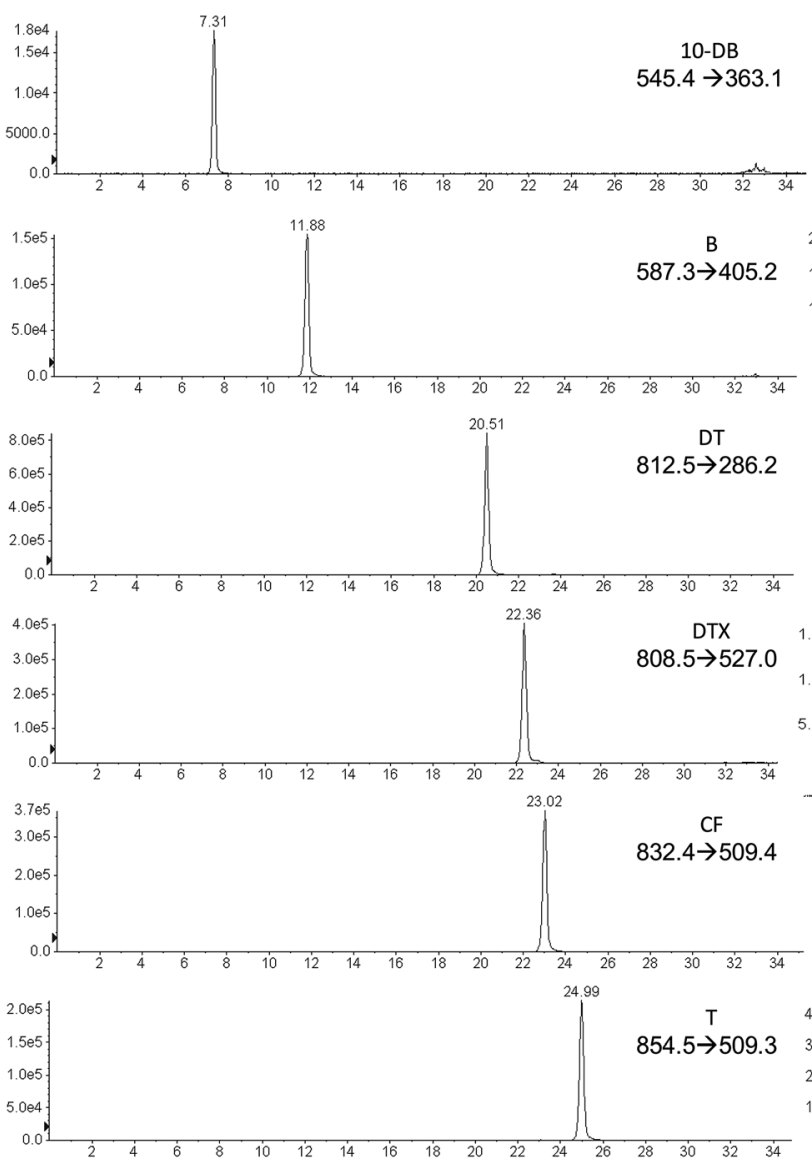

B
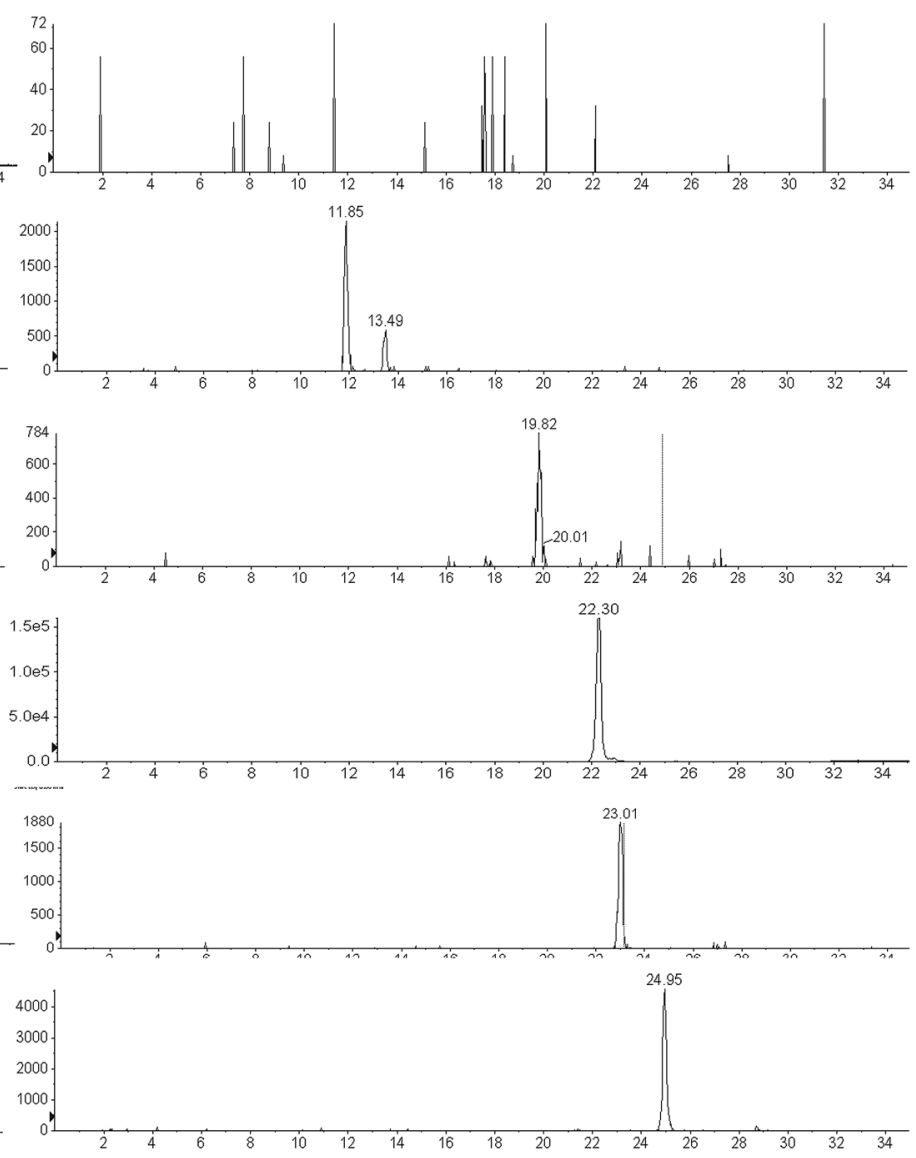

Fig. 3 Identification chromatograms for taxane traces, (a) standard solution at $1.2 \mu \mathrm{g} \mathrm{mL}^{-1}$ with $1 \mu \mathrm{g} \mathrm{mL}{ }^{-1} \mathrm{DTX}$ as IS. (b) C. avellana sample with $1 \mu \mathrm{g} \mathrm{mL}{ }^{-1} \mathrm{DTX}$.

\subsection{Limits of detection and quantification}

Limits of detection and quantification were determined taking into account the matrix effect. With this aim, $C$. avellana samples from non-taxane-containing cell lines were considered as blank samples and therefore spiked to obtain a concentration of $0.3 \mu \mathrm{g} \mathrm{mL}{ }^{-1} . S / N=3$ and $S / N=10$ were used to determine LOD and LOQ, respectively. The LOD was 37.6 $\mathrm{ng} \mathrm{mL^{-1 }}$ for DB, $2.42 \mathrm{ng} \mathrm{mL}^{-1}$ for B, $0.24 \mathrm{ng} \mathrm{mL}^{-1}$ for DT, 0.53 $\mathrm{ng} \mathrm{mL}^{-1}$ for $\mathrm{CF}$ and $0.79 \mathrm{ng} \mathrm{mL}^{-1}$ for $\mathrm{T}$. The LOQ was also determined for all the compounds, being $125.5 \mathrm{ng} \mathrm{mL} \mathrm{m}^{-1}$ for $\mathrm{DB}, 8.0 \mathrm{ng} \mathrm{mL} \mathrm{m}^{-1}$ for $\mathrm{B}, 0.80 \mathrm{ng} \mathrm{mL} \mathrm{m}^{-1}$ for DT, $1.8 \mathrm{ng} \mathrm{mL} \mathrm{mL}^{-1}$ for $\mathrm{CF}$ and $2.7 \mathrm{ng} \mathrm{mL^{-1 }}$ for $\mathrm{T}$. No taxanes were found in the blank sample, although they may have been present below the detection limit.

\subsection{Precision and accuracy}

Intra- and inter-assay precision and accuracy were determined by assaying eight replicates of an intermediate concentration $\left(1.2 \mu \mathrm{g} \mathrm{mL}{ }^{-1}\right)$. The calculated concentrations from the appropriate standard curve in each analytical run were used to obtain the relative standard deviation (RSD). Accuracy was assessed as the percentage of RSD from the theoretical concentration. These parameters are described in Table 2. Intra-day repeatability reached a maximum RSD of $7 \%$ and accuracy ranged between $82-119 \%$ RSD. Inter-day repeatability RSD was always lower than 15\% and accuracy was between $98-104 \%$. Taking into account all these parameters, we developed a reliable and reproducible method, with a repeatability not exceeding $15 \%$ RSD and an accuracy always within the range of 80-120\%. Additionally, the RSD of the retention times was calculated for all the runs and was always lower than $1 \%$ for all the compounds, again illustrating the chromatographic robustness of the method.

\subsection{Recovery accuracy and matrix effect}

Many parameters can influence sample analysis, two of the most important being recovery and the matrix effect. Recovery is based on the amount of product collected after the extraction method. In complex matrices, such as plant samples, an extraction method providing pure compounds is extremely difficult to develop, so recoveries are usually low. On the other hand, the matrix effect, ion suppression or ion enhancement are due to other compounds in the sample interfering with the detection of the target compounds. The taxane standard solution was added to $5 \mu \mathrm{g} \mathrm{mL}{ }^{-1}$ C. avellana culture medium before the extraction to analyze recovery, 
and then after the extraction to analyze the matrix effect. Calculated concentrations were compared with the theoretical concentration added. Recovery by this methodology was $100 \%$ for DB, $86.2 \%$ for B, $84.6 \%$ for DT, $82.9 \%$ for CF and $87.5 \%$ for $\mathrm{T}$. These percentages were obtained taking into account the calculated suppression for each compound. The results showed a matrix effect of $-44.4 \%$ for $\mathrm{DB}, 49.9 \%$ for $\mathrm{B}$, $42.6 \%$ for DT, $43.4 \%$ for $\mathrm{CF}$ and $42.9 \%$ for $\mathrm{T}$ in comparison with the responses achieved when injecting the methanolic solution. The high efficiency of the extraction method and the sensitivity of the system allowed us to detect our compounds despite a certain degree of suppression in our analytical process.

\subsection{Matrix-matching calibration curve}

The same range of taxane concentrations as in the standard curve were added to the $C$. avellana cell culture medium extracts from non-taxane-containing cell lines to obtain a calibration curve. Linearity of the calibration curve was analyzed for all the compounds, showing an $r^{2}$ of 0.987 for DB, 0.993 for B, 0.992 for DT, 0.986 for CF and 0.984 for T. Weighting of $1 / x^{2}$ was applied to obtain an accuracy of $80-120 \%$, while real accuracies were 92.5-114\%. Fig. 3 shows the MRM transitions (identification) for standard compounds (A) and for a sample of C. avellana cell culture medium from a producer cell line (B), detecting and quantifying $\mathrm{B}, \mathrm{CF}$ and $\mathrm{T}$. The ion ratios between the confirmation and identification transition were calculated and compared with those obtained in the standard, allowing us to confirm the presence of the compound when the difference was less than $20 \%$. The $C$. avellana medium extract was quantified using the matrix-matching calibration curve, obtaining a concentration of $120 \mathrm{ng} \mathrm{mL} \mathrm{m}^{-1}$ for $\mathrm{B}, 151 \mathrm{ng} \mathrm{mL} \mathrm{m}^{-1}$ for $\mathrm{CF}$ and $105 \mathrm{ng} \mathrm{mL}^{-1}$ for T. Taking into account the original volume of medium extracted $(20 \mathrm{~mL})$, concentrations of $0.5 \mathrm{ng} \mathrm{mL}^{-1}$ for $\mathrm{B}, 0.63 \mathrm{ng} \mathrm{mL} \mathrm{m}^{-1}$ for

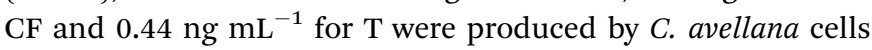
and released into the medium. These results had been confirmed in the extract using HPLC-ITD-FTMS by comparing their retention times with those of standards previously injected in the same conditions and by the exact mass $[\mathrm{M}+\mathrm{H}]^{+}$of the ions present in the FTMS spectra with an accuracy of $\pm 2 \mathrm{mDa}$.

It is therefore possible to affirm that $C$. avellana is a taxaneproducing plant, although the concentrations obtained were very low in comparison with those obtained in Taxus spp. ${ }^{19}$ The analysis was carried out at day 3 of the cell suspension culture because of the low taxane concentration obtained at that point. The developed method is therefore sufficiently sensitive to detect taxane production from the beginning of the culture, when the production is usually extremely low. Razaei et al. (2011) reported a taxol content of $13 \mu \mathrm{g} \mathrm{L}^{-1}$ in the medium of a C. avellana cell suspension culture growing in control conditions at day 12 by HPLC-UV analysis..$^{12}$ Bemani et al. (2013) reported $16 \mu \mathrm{g} \mathrm{L}^{-1}$ of extracellular taxol at day 14 , quantified by HPLC-UV and confirmed by HPLC-MS, but no information about taxol production in the early stages of culture and quantitation by HPLC-MS/MS has been previously reported. ${ }^{20}$

\section{Conclusions}

We have developed and optimized a reliable and sensitive HPLC-MS/MS method to determine five of the most commercially important taxanes (taxol, baccatin III, 10-deacetylbaccatin III, 10-deacetyltaxol and cephalomannine) present at a nanogram level in a Corylus avellana cell suspension culture medium. The culture media of $C$. avellana, a potential new source of taxanes, is of particular interest, as it facilitates the in situ recovery of the product and promotes a continuous production by the cells. In addition, extracellular availability of the target compounds is crucial for scaling up the process.

This new analytical procedure is able to detect secreted taxanes even at the beginning of the culture, when the production is usually extremely low, and allows the production profile to be followed throughout the assay. To the best of our knowledge, this is the first reported application of a liquid chromatographytandem mass spectrometry method to quantify individual taxanes in Corylus avellana, and to evaluate linearity, precision, accuracy, recovery, and the matrix effect, as well as to develop a matrix-matching calibration curve to quantify more precisely the lower concentration of these compounds.

\section{Acknowledgements}

We thank the Centres Científics i Tecnologics of the Universitat de Barcelona (CCiTUB) for their help. This research has been supported by a grant from the Spanish MEC (BIO2011-29856CO2-01) and a grant from the Catalan Government (2014SGR215). A. Gallego was supported by a fellowship from the University Pompeu Fabra.

\section{References}

1 M. Wani, H. Taylor, M. Wall, P. Coggon and A. McPhail, J. Am. Chem. Soc., 1971, 93, 2325-2327.

2 Y. F. Wang, Q. W. Shi, M. Dong, H. Kiyota, Y. C. Gu and B. Cong, Chem. Rev., 2011, 111, 7652-7709.

3 J. A. Yared and K. H. R. Tkaczuk, Drug Des., Dev. Ther., 2012, 6, 371-384.

4 W. P. McGuire, E. K. Rowinsky, N. B. Rosenshein, F. C. Grumbine, D. S. Ettinger, D. K. Amstrong and R. C. Donehower, Ann. Intern. Med., 1989, 111(4), 273-279.

5 F. A. Holmes, R. S. Walters, R. L. Theriault, A. U. Buzdar, D. K. Frye, G. N. Hortobagyi, A. D. Forman, L. K. Newton and M. N. Raber, J. Natl. Cancer Inst., 1991, 83, 1797-1805.

6 M. W. Saville, J. Lietzau, J. M. Pluda, W. H. Wilson, R. W. Humphrey, E. Feigel, S. M. Steinberg, S. Broder, R. Yarchoan, J. Odom and I. Feuersten, Lancet, 1995, 346, 26-28.

7 E. A. Eisenhauer and J. B. Vermorken, Drugs, 1998, 55, 5-30. 8 P. B. Schiff, J. Fant and S. B. Horwitz, Nature, 1979, 277, 665667.

9 A. Hoffman, W. Khan, J. Worapong, G. Strobel, D. Griffin, B. Arbogast, D. Barofsky, R. Boone, L. Ning, P. Zheng and P. Daley, Spectroscopy, 1998, 13(6), 22-32. 
10 L. Ottaggio, F. Bestoso, A. Armirotti, A. Balbi, G. Damonte, M. Mazzei, M. Sancandi and M. Miele, J. Nat. Prod., 2008, 71, 58-60.

11 F. Bestoso, L. Ottaggio, A. Armirotti, A. Balbi, G. Damonte, P. Degan, M. Mazzei, F. Cavalli, B. Ledda and M. Miele, BMC Biotechnol., 2006, 6, 45.

12 A. Rezaei, F. Ghanati, M. Behmanesh and M. MokhtariDizaji, Ultrasound Interact. Biol. Med., 2011, 37, 1938-1947.

13 E. H. Kerns, K. J. Volk, S. E. Hill and M. S. Lee, J. Nat. Prod., 1994, 57, 1391-1403.

14 S. Li, Y. Fu, Y. Zu, R. Sun, Y. Wang, L. Zhang, H. Luo, C. Gu and T. Efferth, J. Pharm. Biomed. Anal., 2009, 49, 81-89.
15 T. Murashige and F. Skoog, Physiol. Plant., 1962, 15, 473-497. 16 M. M. Kiser and J. W. Dolan, LC Trobleshooting, 2004, 17, 138-143.

17 T. D. McClure, K. H. Schram and M. L. J. Reimer, J. Am. Soc. Mass Spectrom., 1992, 3, 672-679.

18 G. Corona, C. Elia, B. Casetta, S. Frustaci and G. Toffoli, Clin. Chim. Acta, 2011, 412, 358-364.

19 S. Malik, R. M. Cusidó, M. H. Mirjalili, E. Moyano, J. Palazon and M. Bonfill, Process Biochem., 2011, 46, 23-34.

20 E. Bemani, F. Ghanati, A. Rezaei and M. Jamshidi, J. Nat. Med., 2013, 67, 446-451. 